\title{
Protection against suspended sand: the function of the branchial membrane in the blue mussel Mytilus edulis
}

Received: 17 May 2005/ Revised: 2 January 2006/ Accepted: 3 January 2006/Published online: 7 February 2006 (c) Springer-Verlag and AWI 2006

\begin{abstract}
Blue mussels (Mytilus edulis) living in estuaries have to cope with varying concentrations of suspended sand. Sand flowing through the inhalant siphons comes into the infrabranchial chamber. The inhalant siphon can be partially closed by the branchial membrane. As a result the inward flow decreases, and suspended sand sinks and can be eliminated. Experiments with mussels from three ecologically different locations showed about the same response of the branchial membrane on contact with suspended sand. The presence and function of the branchial membrane appears to be an adaptation of mussels to their estuarine environment.
\end{abstract}

Keywords Mytilus edulis · Branchial membrane · Suspended sand

\section{Introduction}

In estuaries, strong tidal currents and turbulence caused by high winds bring large amounts of sand in suspension. Blue mussels living there possess mechanisms to eliminate sand from the mantle cavity. Ciliary particle transport on the surface of the visceral mass, the palps and the whole mantle surface has been described (Wallengren 1905; Kellogg 1915). An important ciliary tract runs along the ventral inner surface of the inner mantle lobe, transporting material to the ventral part of the inhalant siphon, whence it is eliminated just below the strong exhalant stream (Dodgson 1928; Orton 1912).

Communicated by H.-D. Franke

C. G. N. de Vooys

Royal Netherlands Institute for Sea Research, 1790 AB Den Burg, PO box 59, Texel,

The Netherlands

E-mail: cdvooys@nioz.nl

Tel.: + 31-0222-369300

Fax: + 31-0222-319674
Blue mussels in natural banks in estuaries are attached with their ventral side on the substrate. The ciliary tract along the inner fold of the mantle edge is well situated for the elimination of waste particles (Orton 1912). Blue mussels may also have a mechanism to reduce the influx of sand into the mantle cavity. They possess a branchial membrane, situated dorsally in the inhalant siphon. This membrane can be lowered, closing in part the inhalant siphon and directing the inhalant water current into a ventral direction (Dodgson 1928; White 1937). Experiments were carried out to test the hypothesis that the branchial membrane has a function in limiting the influx of sand. Mussels from three different environments were tested: coastal water, Wadden Sea channels and a tidal shallow bay.

\section{Materials and methods}

Experimental animals

Blue mussels (Mytilus edulis L.) from three different localities were used in the experiments. Sublittoral mussels were obtained by dredging from a depth of 5$6 \mathrm{~m}$ at the Doove Balg, Western Dutch Wadden Sea. Littoral mussels were collected by hand on the north shore of the Mok Bay at the lower end of the dike. North sea mussels were collected from the bottom of a buoy about 8 mile W of De Koog, Texel $\left(53^{\circ} 10^{\prime} 57^{\prime \prime} \mathrm{N}\right.$, $4^{\circ} 35^{\prime} 19^{\prime \prime} \mathrm{E}$ ); the depth on this location is about $20 \mathrm{~m}$. Only the largest animals were used for the experiments. The mussels were kept in aquaria of about 401 with running aerated sea water $\left(16^{\circ} \mathrm{C}, 30-32 \%\right)$ till use. Age of the sublittoral Wadden Sea mussels was between 2 and 3 years, the buoy mussels were maximal 2 years and 4 months old, and the littoral Mok Bay mussels were at least 6-7 years old.

All experimental work was carried out in autumn 2004. Mussels from the Mok Bay were tested in September and October, those from Doove Balg and the North Sea buoy in November and December. 
Experiments with sand

Sand was collected on the beach north of the Institute and sieved. Two fractions were used in the experiments: 160-250 and 100-160 $\mu$.

The experiments were carried out in an aquarium room at a temperature of $17^{\circ} \mathrm{C}$. Mussels were held open with wooden wedges (width of 5 or $7.5 \mathrm{~mm}$ ). They were placed in the aquaria with their inhalant siphon ready for particle capture. A suspension of sand and sea water was pipetted above the mussels. Individuals were given this treatment twice successively. The response of the branchial membrane on contact with the suspended sand was observed (Fig. 1). Because the mussel mantle responded to light, the aquarium room was kept in the dark and observations were made by light of a small pocket torch. Temperature and salinity of the sea water used in the experiments were measured with a WTW microprocessor conductivitymeter LF 196 (Weilheim, Germany).

\section{Video recording}

Movement of the branchial membrane in response to suspended sand was recorded with a Sony Handicam video camera with a macro-lens situated vertically above the experimental set-up (Fig. 1). From the video footage, pictures were selected which show the movement of the membrane in three cases with mussels from each location (Fig. 2).

\section{Characteristics of the experimental animals}

Live weight, length of the shells and weight of the shells as well as of the flesh were determined. Dry weight of the

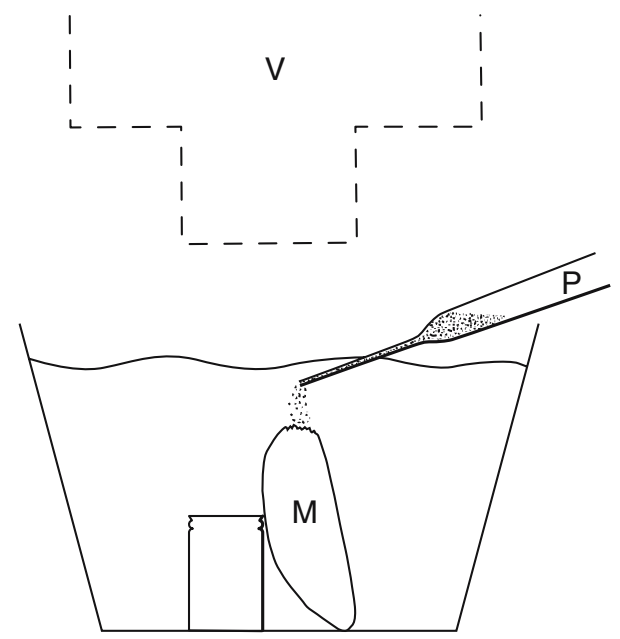

Fig. 1 Experimental set-up for branchial membrane tests; $M$ mussel, $P$ Pasteur pipette with sand and water mixture, $V$ video recorder flesh was determined by drying the samples for 3 days at $60^{\circ} \mathrm{C}$.

Statistical analysis

The proportion and magnitude of branchial membrane responses were compared between locations using a $G$-test. Differences in condition factors of experimental mussels from different locations were tested by ANOVA analysis and Bonferroni pairwise comparisons.

\section{Results}

Response to suspended sand

The majority of the mussels showed responses of the branchial membrane when suspended sand was added (Fig. 2). The responses occurred fast within about a tenth of a second. The proportion of positive responses did not differ significantly between the three groups (Table 1; $G$-test, $G=0.62, P=0.73$ ) and there were also no differences in the magnitude of responses. Most experiments were carried out with a sand fraction of $160-250 \mu$ in grain size; in a few experiments where also sand with $100-160 \mu$ grain size was applied, the same results were obtained.

Characteristics of the experimental animals

Mean length of the subtidal Wadden Sea mussels sampled was $6.67 \pm 0.32 \mathrm{~cm}(n=60)$, for the buoy mussels $7.95 \pm 1.01 \mathrm{~cm}(n=40)$ and for the littoral Mok Bay mussels $6.07 \pm 0.40 \mathrm{~cm}(n=34)$. Characteristics of the mussels used in the experiments are given in Table 2. Mussels from the three locations differed significantly with respect to the studied variables: wet weight, shell weight, dry weight and shell length (ANOVA, $P<0.001$ for all variables). Bonferroni-corrected pairwise comparisons showed that Doove Balg mussels differed from buoy De Koog mussels for all variables, except for dry weight.

\section{Discussion}

Molluses living in estuaries need some adaptation to suspended sand in their environment. However, the only work on this subject has been performed because of the practical value in the desanding of reared mussels (de Vooys 1987; Lui and Leung 2004).

Anatomical descriptions of the branchial membrane of M. edulis were given by Kellogg $(1890,1915)$, Field (1922), Dodgson (1928) and White (1937). Dodgson (1928) suggested that the branchial membrane (which he called "velum") could limit the influx of sand into the 
Fig. 2 Pictures from video recording of branchial membrane response to suspended sand; arrows indicate the front edge of the membrane. $A$ Mok Bay mussel, $B$ Doove Balg mussel, $C$ Mussel from buoy off De Koog
A
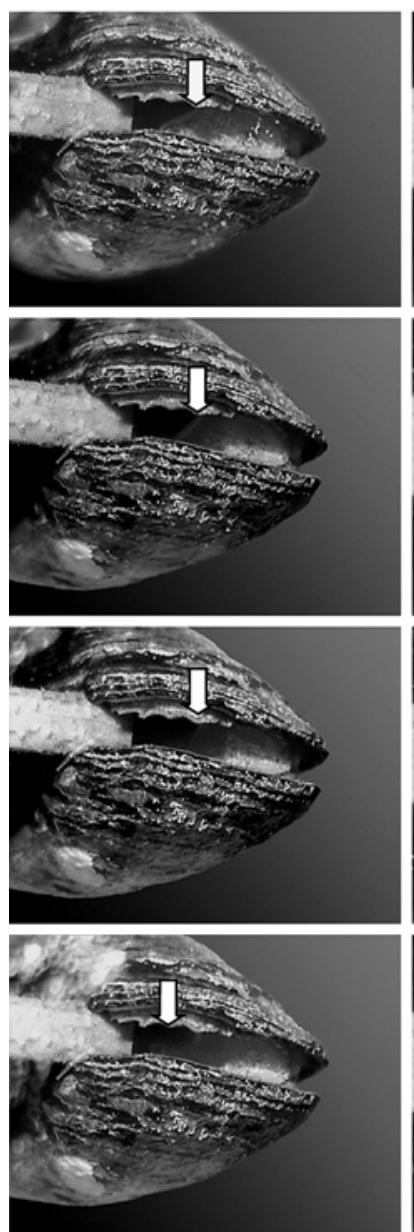

B
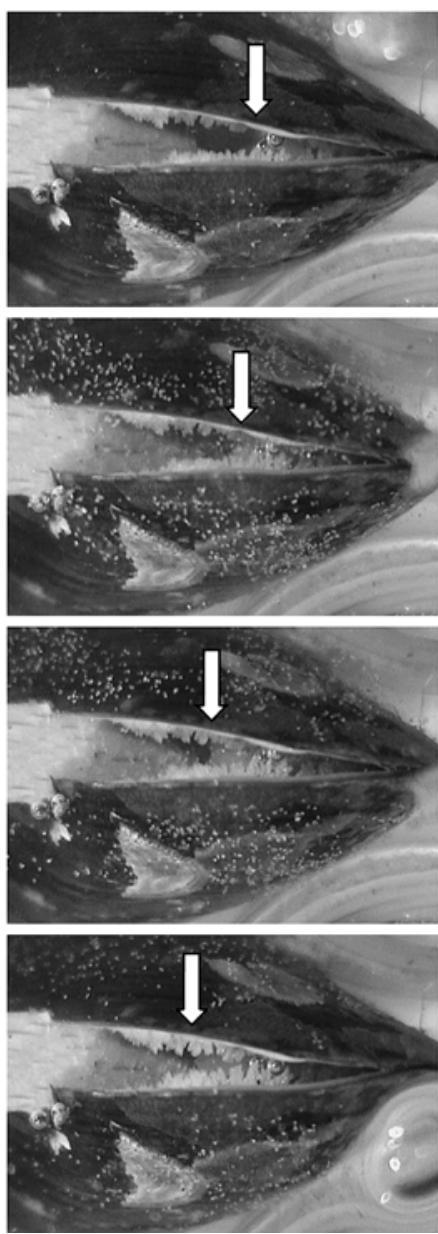

C
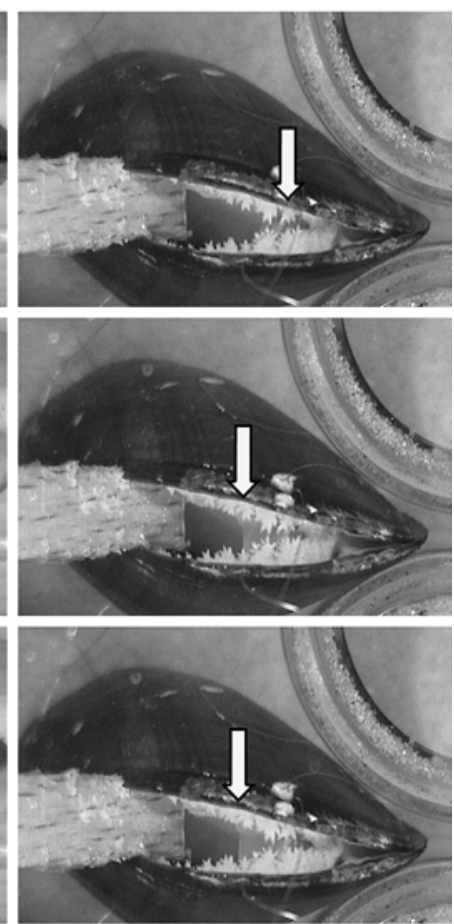

Table 1 Responses of the branchial membrane to suspended sand in mussels from three different locations (in parentheses, \%)

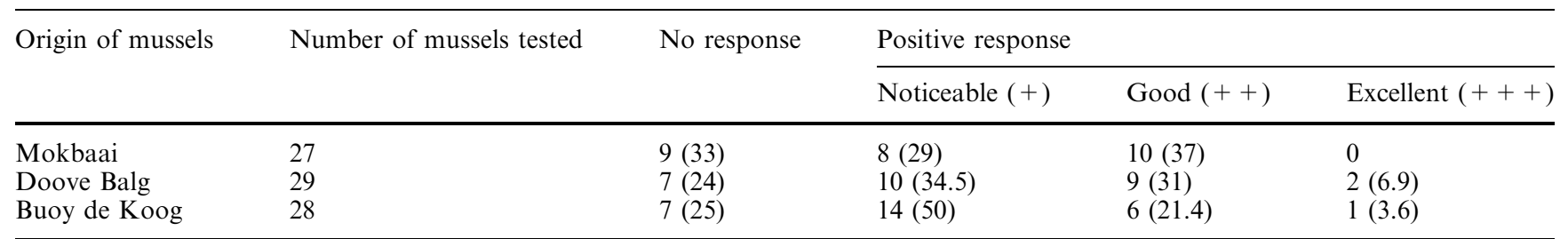

mantle cavity. Alternatively, the branchial membrane was suggested to decrease filtration by reducing the watermass pumped by the gills (Dardignac-Corbeil 1976). In the experiments described here, responses of the branchial membrane to suspended sand were demonstrated in mussels from all three locations.
Blue mussel beds occur either intertidally or subtidally in the Wadden Sea. Sand suspension is high and variable because of the tide, and is therefore expected to interfere with filtration. Protection could be provided by valve closure; however, the cost would be a stop of feeding. Instead, the lowering of the branchial mem-

Table 2 Condition of mussels of different locations used in the experiments (in parentheses, $N$ )

\begin{tabular}{lllll}
\hline Origin of mussels & Wet weight (\% of live weight) & Shell weight (\% of live weight) & Dry weight (\% of wet weight) & Shell length (cm) \\
\hline Mokbaai & $12.80 \pm 2.48(32)$ & $48.00 \pm 3.8(32)$ & $19.00 \pm 1.93(32)$ & $6.07 \pm 0.40(34)$ \\
Doove Balg & $22.91 \pm 3.32(43)$ & $34.90 \pm 2.1(43)$ & $22.71 \pm 2.43(45)$ & $6.77 \pm 0.31(45)$ \\
Buoy De Koog & $26.10 \pm 6.27(42)$ & $31.20 \pm 2.81(42)$ & $22.76 \pm 4.23(50)$ & $7.95 \pm 1.01(40)$ \\
\hline
\end{tabular}



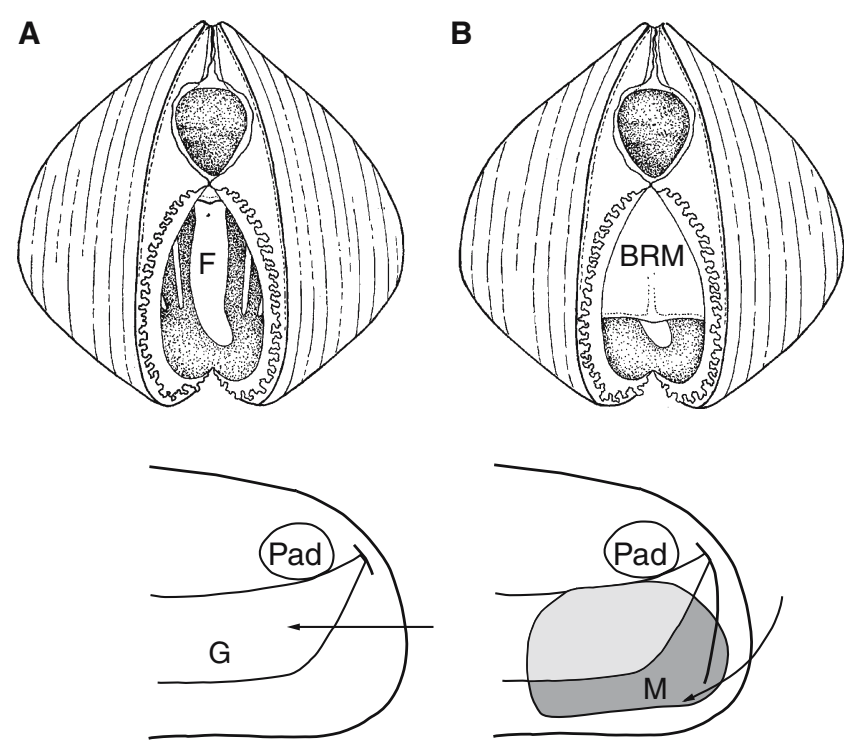

Fig. 3 Drawing of the lowering of the branchial membrane (above, a and b) and outline of the direction of the inflow current at a contracted (left) and a lowered (right) branchial membrane. Part of the mantle surface with higher activity in eliminating sand is indicated. $B R M$ branchial membrane, $F$ foot, $G$ gill, $P a d$ posterior adductor muscle

brane decreases the inflow and directs it downwards. The suspended sand will sink ventrally and can be removed by the cilia tract in the inner mantle fold. The mantle surface near the inhalant siphon has the greatest sand removing capacity (Fig. 3).

The closing of the branchial membrane enables filtration to continue, although at a lower level, during the entire tidal cycle. The presence of a branchial membrane in the mussel is an indication of a good adaptation to living in estuaries.

Mussels on a floating buoy in coastal waters 8 miles $(15 \mathrm{~km})$ off the coast are living in an environment with little suspended sand in the water column.

Nevertheless, no difference in the occurrence and magnitude in the response of the branchial membrane was found. The results of this investigation indicate that the function of the branchial membrane does not change according to the particular environment mussels come exposed to.
Other bivalve species living in sandy estuaries do not have a branchial membrane. They probably use other mechanisms to eliminate sand from their infrabranchial chamber. In Macoma balthica, for example, the sand taken in with the food is, from time to time, blown out again by reversing the water current in the inhalant siphon. In Mya arenaria and Cerastoderma edule, a sudden adduction of the shells occurs and the outflow of the water from the infrabranchial chamber eliminates the accumulated sand. However, our knowledge on the adaptation to suspended sand in animals which live in estuaries is still rather incomplete.

Acknowledgements The author wishes to thank R.P.D. Aggenbach and G.M. Manshanden for performing the video recordings and editing the video pictures, and Dr J. van der Meer for carrying out the statistical analysis of the results. Also he thanks C.M. Minnes (Ministery of Transport, Public Works and Water Management) and the crew of the m.s. "Phoca" for providing mussels from the coastal buoy and the Western Wadden Sea, respectively.

\section{References}

Dardignac-Corbeil MJ (1976) La moule. Biologie de l' huître et de la moule. Rev Trav Inst Pêches Marit 40:315-345

Dodgson RW (1928) Report on mussel purification. Fish Invest Ser II X(1):154-223

Field IA (1922) Biology and economic value of the sea mussel Mytilus edulis. Bull US Bur Fish 38:127-259

Kellogg JL (1890) A contribution to our knowledge of the morphology of the lamellibranchiate molluscs. Bull US Fish Comm 10:389-436

Kellogg JL (1915) Ciliary mechanisms of lamellibranchs, with descriptions of anatomy. J Morphol 26:625-701

Lui KK, Leung KMY (2004) Sand elimination by the Asiatic hard clam Meretrix meretrix (L.): influences of temperature, salinity and season. J Shellfish Res 23:421-427

Orton JH (1912) The mode of feeding of Crepidula, with an account of the current-producing mechanism in the mantle cavity, and some remarks on the mode of feeding in gastropods and lamellibranchs. J Mar Biol Assoc UK 9:444-478

de Vooys CGN (1987) Elimination of sand in the blue mussel Mytilus edulis Neth J Sea Res 21:75-78

Wallengren H (1905) Zur Biologie der Muscheln. II. Die Nahrungsaufnahme. Acta Univ Lund (n.ser.) Afd 2, Bd 1, nr 3:1-59

White KM (1937) Mytilus. L.M.B.C. Memoirs on typical British marine plants and animals. In: Daniel RJ (ed), no 31 